\title{
LA NOVELA FAMILIAR: CLAVES HISTORICISTAS EN LA "NOVELA CORTA” DE JOSÉ MARÍA VARGAS VILA
}

\author{
POR \\ José M. GARCíA-SÁNCHEZ \\ Eastern Washington University
}

El raudal de polémicas y diatribas generado en torno al Modernismo hispanoamericano durante varias décadas ha producido un sinfín de tópicos que a menudo emergieron no en la búsqueda de esclarecer disyuntivas, sino de ahondar en rémoras institucionales. Parece que después de varias décadas de disputas, unas apasionadas, insulsas las otras, las aguas han abierto un cauce de sobriedad y de múltiples estudios socioculturales que han aportado una visión interdisciplinar sobre los diferentes modernismos que se incubaron en el atlas geopolítico europeo y americano. A raíz de esos mismos estudios socioculturales, muchas disputas se ofrecen a ojos del siglo XXI, si no obsoletas, epítomes reflexivos del fin de siglo.

Los modernismos que concurrieron en Hispanoamérica a finales del siglo XIX han dejado cicatrices institucionales difíciles de olvidar, ya sea por su estatus canónico, por su aproximación metodológica o por su visión elitista. La figura del colombiano José María Vargas Vila (1860-1933) contribuyó en gran medida, por su cariz subversivo, como agente y agencia de estas disputas. Ignorado por la crítica, Vargas Vila se consolidó como uno de los primeros representantes de los superventas en Hispanoamérica, o del concepto sajón del "bestsellerismo". El autor colombiano probablemente nunca llegará a ser un clásico literario, sin embargo su populismo ideológico definió el panorama social y cultural panhispánico de su época al contribuir con su narrativa a la educación de un gran número de lectores y desvincular al modernismo de su supuesto elitismo.

A pesar de la insistencia constante de los estudiosos en reclamar espacios aislados, las características intrínsecas del espacio geopolítico hispanoamericano de comienzos de siglo XX demanda de los investigadores un espíritu crítico que incorpore esta perspectiva y contraste. En esa línea de intercambio trasatlántico, el análisis discursivo al que nos dedicamos se circunscribe a las publicaciones de José María Vargas Vila en la serie la Novela corta publicadas en España, un trabajo que se desprende de mis investigaciones ya iniciadas en el estudio La Novela corta de José María Vargas Vila (2000). El tema de investigación se concentra en un asunto reiterativo de sus obras: la familia de fines del 
siglo XIX. Las variantes aristocrática, burguesa y proletaria del complejo familiar son la piedra angular de la obra de Vargas Vila. La familia se constituye en un laboratorio ensayístico donde los personajes nacen y crecen a la par de sus lectores, aleccionándose, vituperándose, recriminándose, hasta tal punto que la tesitura novelesca y el retrato social se hacen parte de un mismo fenómeno. Frente a los escritores modernistas que por lo general se nombraron a sí mismos como adalides de la causa antiburguesa, Vargas Vila se convirtió contradictoriamente en la fusta burguesa más leída por la flamante y proliferante clase media que se veía retratada, enjuiciada, examinada y diagnosticada en sus novelas. La figuración del ente familiar como recurso de la representación nacional y social supuso una de las metáforas más productivas en la orquestación política y narrativa internacional y por supuesto, Hispanoamericana. Vargas Vila compendió tales representaciones repetidamente bajo una fórmula exitosa. Su público incondicional lo arropó incluso después de su muerte con la compra de sus obras, mientras que la crítica prefirió hacer una mención a pie de página u omitir su obra. ${ }^{1}$

$\mathrm{Su}$ escritura revela un periodo violento y de escepticismo que el autor bogotano vislumbró al hacerse voz de una causa popular que no encontró eco en el academicismo imperante, tal vez por la incomodidad que suponía para esa clase intelectual defender un punto de vista que ciertos sectores de lectores demandaban y que se había construido en torno a la heroína bovarysta, de cariz cervantino:

[El bovarysmo] consistía en una fascinación imposible de controlar por la literatura popular, el folletín, el melodrama y toda clase de efusiones sentimentales. [...] El bovarysmo sería así no el producto de los malos libros, sino el resultado de las malas lecturas de los buenos libros. [...] Las mujeres lectoras, entes domésticos y carentes, convierten la gran literatura y el gran pensamiento en una extensión de su privacidad y de su privación. (Catelli 121; 127)

Más allá de una valoración puramente estética, el muestrario discursivo ideológico presente en José María Vargas Vila merece la máxima atención para discernir los ecos populistas de las voces populares. Si Sigmund Freud nos desveló en La novela familiar del neurótico (1908) los trasuntos psíquicos que confrontaba el individuo en torno

1 De la dificultad para valorar literariamente la obra del colombiano da cuenta el tono irresoluto de la nota necrológica publicada por Arturo Torres Rioseco en Hispania: "Rey de la metáfora, de la repetición, de la onomatopeya y de la barbarie gramatical, el escritor colombiano nos dejó unas cincuenta obras, de las cuales no se salvará ni siquiera una página cuando el tiempo justiciero haga su recuento. Nutrido de la filosofía pesimista de Schopenhauer, de la superhombría nietzscheana y del estudio de la psicopatología, cae en lamentables errores filosóficos y en aberraciones de manicomio. Con todo, la brillantez extraordinaria de su estilo barroco, la vitalidad estupenda de su verbo, el brío en el ataque, lo rotundo de la negación, dieron a sus libros una popularidad continental" (399).

Revista Iberoamericana, Vol. LXXXI, Núm. 252, Julio-Septiembre 2015, 767-785 ISSN 0034-9631 (Impreso) ISSN 2154-4794 (Electrónico) 
al núcleo familiar, Guilles Deleuze en su Antiedipo nos instigó a desenmarañar las implicaciones sociales de ese núcleo: "La novela familiar no se deriva de Edipo: Edipo se deriva de la novela familiar y por ello del campo social" (366). La obra de Vargas Vila, antiedípica por excelencia, es, sin duda, un índice de la producción sociocultural de principio del siglo XX, ávida de un público consumidor de sus propias "neurosis sociales". A este marco de valoración cultural nos atenemos respecto a las obras que el colombiano publicó.

Si el término decadente tuvo su máxima aceptación antimodernista en Hispanoamérica tras la publicación de la obra Entartung (1892) del alemán Max Nordau, -traducida al español por Nicolás Salmerón y García en 1902 (Litvak, España 5)-, quizás la máxima expresión de conceptualización del término se deba a la vida y obra que Vargas Vila encarna en todas sus dimensiones, ya fuera por su escritura, su indumentaria, su estilo de vida o sus disputas políticas y literarias. Vargas Vila no es la secuela directa de las neurosis familiares, sino que utilizó la novela familiar para dar cuenta de las neurosis políticas nacionales acaecidas en todas las esferas internacionales, como lo certifica su éxito de ventas en Hispanoamérica. Mientras los Estados en formación utilizaron la familia como arma política en contra de la decadencia o la degeneración, el colombiano reaccionó contra esos mismos mecanismos de poder institucionalizados, desplazando sus significados, símbolos y emblemas para criticar el poder inquisitivo de los diferentes poderes conservadores y de sus aparatos ideológicos. En este sentido, es interesante observar el éxito y el reclamo populista que alcanzó en Colombia al comienzo de su carrera como resultado de su crítica cáustica contra el presidente Rafael Núñez y que le llevara a su exilio en 1887. Ese mismo éxito y acogida popular fueron los que Vargas Vila disfrutó bajo la dictadura de Primo de Rivera en España, donde galanteó con el gran éxito de sus publicaciones hasta la condena y prohibición de sus libros en la editorial Sopena, y que culminaría con su muerte.

\section{LA NOVELA CORTA}

Respecto al término "novela corta", es necesario distinguir entre el género de la doctrina clásica, la producción industrial y masiva característica de principios del siglo $\mathrm{XX}$, y la serie "La novela corta" que entraría en la producción de novelas cortas y que pudo o no adoptar las "características" del género. La colección "La novela corta" apareció el 15 de enero de 1916, dirigida por José de Urquía en toda su trayectoria editorial hasta el 13 de junio de 1925. Esta serie, además de autores peninsulares consagrados (Gustavo Adolfo Bécquer, Benito Pérez Galdós, Emilia Pardo Bazán, Miguel de Unamuno, Vicente Blasco Ibáñez,), incorporó a varios novelistas que antes no habían participado o lo habían hecho esporádicamente en otro tipo de publicaciones de la misma índole tales como "El cuento semanal", "La novela de hoy", "Los contemporáneos", o "La

Revista Iberoamericana, Vol. LXXXI, Núm. 252, Julio-Septiembre 2015, 767-785 ISSN 0034-9631 (Impreso)

ISSN 2154-4794 (Electrónico) 
novela mundial". ${ }^{2}$ La nómina de "poetas y prosistas americanos" que incluye son, en orden de su fecha de nacimiento, José María Vargas Vila, Amado Nervo, José Enrique Rodó, Leopoldo Lugones, José Santos Chocano, Alberto Insúa y Alfonso Hernández Catá, todos ellos anunciados reiteradamente en diversos números de "La novela corta". Las obras que aquí se recogen corresponden a la época de residencia europea de Vargas Vila, especialmente en Barcelona. Después de su estancia en París (1904) Vargas Vila se dedicó exclusivamente a su vida de escritor, alejado de misiones diplomáticas y de la vida política que tantos recuerdos aciagos le había dejado hasta volver a América Latina en su gira de 1923.

El autor colombiano publicó trece obras en "La novela corta" entre 1916 y 1921: El alma de la raza (1916), El maestro (1917), El motín de los retablos (1917), Sabina (1918), El medallón (1918), El milagro (1919), Otoño sentimental (1919), Orfebre (1919), El rescate (1920), La sembradora del mal (1920), Desiderio (1921), Nora (1921), El pasado (1921). La mayoría de las obras circularon en España e Iberoamérica y algunas de ellas formaron parte en "Prensa Popular" de una serie de recopilaciones titulada Mis mejores cuentos (novela breve) (1920). La vacilación del término "cuento" para referirse a este tipo de publicaciones es significativa respecto a la clasificación, más pronunciada aún por el hecho de ser subtitulada "novela breve". Las publicaciones de "La novela corta", similares a las de otras publicaciones de la época, se caracterizaron por su precio asequible (5 a 10 céntimos de pesetas), por la mala calidad del papel utilizado debido a la crisis papelera española en 1916 (los folletos cosidos con una grapa en el lomo apenas han sobrevivido en las librerías de viejo), por la propaganda consumista en sus contraportadas, por las ilustraciones al gusto de la época, así como por su masiva distribución. Su inmediato predecesor fue el folletín dieciochesco. Su extensión es de veinticuatro a veintiséis páginas. Los títulos de la portada y contraportada están impresos en bicolor: rojo y negro o bien verde y negro. En la portada figura en diferentes poses la fotografía del autor. La contraportada se utiliza para sufragar la publicación con anuncios de la época con productos de calzado, sastrería, decoración, encuadernación, perfumería, o para informar de los precios de suscripción a las publicaciones de la Novela teatral y a la propia Novela corta, entre otras. Todas las obras aparecen subtituladas como obras inéditas en la primera página donde comienza la trama propiamente dicha. Tanto la portada como la contraportada se disponen como intertextos de la misma obra, los cuales codifican un público español de clase media, consumidores de las publicaciones de "Prensa popular".

La obra L'Infra-literature en Espagne hace un preciso recuento de "novelas cortas" que comprende el período de 1904 hasta 1933 (Carrillo 141). La "novela corta" es la colección que más publicaciones tiene después de "La novela de hoy", un total de 499; de ambas, un gran número se encuentra en la Hemeroteca Municipal de Madrid.

Revista Iberoamericana, Vol. LXXXI, Núm. 252, Julio-Septiembre 2015, 767-785 ISSN 0034-9631 (Impreso)

ISSN 2154-4794 (Electrónico) 


\section{HiSTORIA DE UNA POLÉMICA}

La polémica que mantuvo Federica Montseny contra Vargas Vila en España entre los años 1923 y 1925 en La Revista Blanca sucedió dos años después de la publicación de las obras del colombiano. ${ }^{3}$ La divulgación de sus novelas cortas en España sirve de paradigma ilustrativo respecto a lo que sucedió con otras personalidades literarias de la época, donde el rubendarismo, el ramonismo, el unamunismo, el borgismo, y sus partidarios o detractores, van a la par de los vanguardismos estéticos e ideológicos que se sucedieron simultáneamente. Sin embargo la polémica tiene otras dimensiones sociohistóricas y cabe encuadrarla en los procesos de modernización de la sociedad española y en los mecanismos de escape a la censura que el régimen de Primo de Rivera había instaurado respecto a la prensa y respecto a las novelas que tuvieran más de 200 páginas. De ahí que surgen entre 1900 y 1923 una multitud de editoriales cuyo oficio político comprometido es fehaciente:

El período de 1917-1930 está marcado, pues, por una evidente transformación de las condiciones de la producción cultural. Bajo el efecto de factores de orden general, relacionados con el proceso de modernización que conoce la sociedad española, pero también de un determinismo que los afecta de manera particular, los medios y el libro conocen una progresión cuantitativa que aumenta de forma espectacular su impacto sobre el público. (Serrano 67)

El vargasvilismo tuvo también su síntesis polemista dentro del ámbito anarcoliterario en el que se desenvuelven los ideólogos, lectores y artistas de La Revista Blanca. El artículo de Federica Montseny "La obra de los mediocres" (16), alude en un tono de desesperanza a la época de mediocridades en la vida y en la idea misma. Ella percibe una crisis universal caracterizada por la "falta colectiva de energías espirituales y de valores afirmativos" (17) que nos recuerda a la tan conocida definición de Federico de Onís respecto al Modernismo. En ese orden expositivo de mediocridades (vida, idea) que distingue Federica Montseny, Vargas Vila se erige en su "apóstol máximo" (16). Frente a las figuras del anarquismo racional y científico de Kropotkin, Reclus y France, se manifiesta el retoricismo vargasvilista, según Federica Montseny:

No es ahora como mujer, ofendida y ultrajada en el ultraje general al sexo, como combato en este artículo a Vargas Vila.

Lo combato como anarquista y como ser humano. Y combato en él la mediocridad que

3 Federica Montseny (1905-1994), feminista precursora y anarquista, primera mujer ministra de la Segunda República española, pasaría a la historia porque desde su ministerio promulgó una ley del aborto y creó centros de atención y protección para las prostitutas.

Revista Iberoamericana, Vol. LXXXI, Núm. 252, Julio-Septiembre 2015, 767-785 
hace presa en nosotros; la mediocridad que se manifiesta de mil maneras, siendo una de ellas y de las más perjudiciales el vargasvilismo y el amaneramiento en la literatura libertaria y en la misma actuación y modo de ser de muchos anarquistas. (“Obra" 18)

A partir de este artículo se sucede alternativamente un orden de respuestas por parte de los lectores en el que llegan a participar hasta contendientes del continente americano, de ahí que la polémica se prolongue por tres años. Ignacio Cornejo interviene como mediador en la polémica al consentir que ha sido admirador de Vargas Vila, aunque prefiere que se haga una relectura de su obra para recomendarla a los lectores. Como respuesta al tono de apaciguamiento de la figura literaria de Vargas Vila por parte de Cornejo, la misma Federica Montseny responde señalando que tiene una buena parte de su producción, pero librada la suerte de las alabanzas arremete contra la figura del colombiano y su vida privada.

En la publicación de La Revista Blanca de octubre de 1924, Juan Serret, desde Santiago de Cuba, hace una defensa unánime de la figura vargasvilesca y sobre todo de la obra Ibis:

Yo no me explico cuál es la causa de que existan compañeras que vean en Vargas Vila un enemigo, y otras a un sincero amigo de la emancipación de la mujer y un verdadero adalid de la Libertad. En esta ciudad hay una compañera que propaga y ama nuestro ideal con la misma actividad y pasión que pueda hacerlo la compañera Montseny; y ella manifiesta que Ibis es una de las novelas-cumbres de Vargas Vila. ("Vargas Vila" 39)

Por parte de Montseny, la respuesta no se hace esperar en su artículo "Más sobre Vargas Vila" del quince de febrero de 1925:

No creo que Juan Serret estime que a latigazos se dignifica a los hombres. Se les dignifica con ejemplos y palabras nobles; se les liberta con razonamientos, sacrificios y esfuerzos generosos; jamás con ultrajes ni con burlas. (1)

Esta vez la respuesta de Ignacio Cornejo, titulada "Sobre Vargas Vila y sus obras", abunda en las precisiones de Federica Montseny atendiendo a la utilización de la mujer como eje de victimización y desestimando el tono "libertario" de Ibis. Federica Montseny vuelve a las precisiones respecto al vargasvilismo, identificándolo con la renegación e incluso el "fracaso sexual". La contrarrespuesta de Juan Serret, "Un poco más sobre Vargas Vila", aparece el quince de julio con continuación el 1 de agosto de 1925. Su comentario alude a los reproches de la indisciplina gramatical vargasvilesca, y en la segunda parte de la carta completa su defensa del escritor colombiano con la "revolución moral" (38) a la que debe incitar la lectura de Vargas Vila. En el número del quince de septiembre del mismo año, y como broche final titulado "Las mujeres y

Revista Iberoamericana, Vol. LXXXI, Núm. 252, Julio-Septiembre 2015, 767-785 ISSN 0034-9631 (Impreso) 
Vargas Vila", se incluyen otras cartas a propósito de la polémica iniciada. Participan en ella Julia Acosta desde Santiago de Cuba con una carta titulada "Contestando un saludo" (37) y otra desde España de Matilde Mota titulada “Otra opinión sobre Vargas Vila y su obra" (37-38), defendiendo ambas a José María Vargas Vila. La carta final de Federica Montseny, también titulada "Las mujeres y Vargas Vila" del primero de octubre de 1925, reprocha a Vargas Vila que no participe en la polémica, aunque difícilmente éste hubiera podido responder inmediatamente por encontrarse en viaje por Iberoamérica. La carta se sube de tono en los ataques personales y acusa a Vargas Vila de morfinómano, de reaccionario y por su posición provechosa de diplomático (1).

Los ánimos políticos en la península estaban en su vertiente más crítica pues la instauración de la dictadura de Primo de Rivera (1923-1930) hizo que el desconcierto popular fuera patente. Es preciso considerar que los ataques de Vargas Vila hicieron eco en la opinión pública pues señalaban la amenaza de las grandes potencias que se cernía sobre Iberoamérica y el surgimiento de los propios dictadores hispanoamericanos. También es posible constatar en la misma polémica la predilección de Montseny por caracterizar la crítica de la obra sobre la base de la crítica personal del autor y no en relación con el poder de aglutinamiento político que los lectores cubanos prefieren y en el que Vargas Vila ocupaba un espacio predilecto por sus críticas a las dictaduras latinoamericanas.

Aunque bien se pudiera entrar en un análisis abstracto acerca de la configuración de los lectores, de sus implicaciones políticas, el análisis de la polémica se puede contemplar también desde el margen panóptico que la crítica en esos momentos adoptara. La Revista Blanca fue publicada por primera vez en 1898, por el matrimonio Soledad Gustavo y Federico Urales, cuyo nombre verdadero era Joan Montseny, anarquista catalán perseguido y padre de Federica Montseny, nacida en 1905. No es el régimen centralizado de la ley, según Foucault en Las palabras y las cosas, el que funciona o se diluye en su control, sino a través de los regímenes de comercialización e industria moderna como se distribuía ese poder y control en busca de una "verdad" que nunca existió:

En esa humanidad central y centralizada, efecto e instrumento de relaciones de poder complejas, cuerpos y fuerzas sometidos por dispositivos de "encarcelamiento" múltiples, objetos para discursos que son ellos mismos elementos de esta estrategia, hay que oír el estruendo de la batalla. (314)

La polémica no deja de ser amena y seguramente despertó más adeptos o detractores de la obra del colombiano. Como quiera que sea, es posible que incrementara el número de ventas y que el autor agradeciera a ambas partes su consideración sobre los asuntos tratados. Nos parece interesante constatar la percepción dispar tan diferente del fenómeno "Vargas Vila" entre los lectores masculinos y femeninos de ambos lados del Atlántico.

Revista Iberoamericana, Vol. LXXXI, Núm. 252, Julio-Septiembre 2015, 767-785 ISSN 0034-9631 (Impreso)

ISSN 2154-4794 (Electrónico) 
José Carlos Mainer en su artículo "La novela corta" distinguió este tipo de publicaciones respecto a la novela extensa por su brevedad, la trama lineal y nítida, los pocos personajes que la pueblan, y la intensificación de una atmósfera que impregna todo el relato. La trama normalmente constituye el desarrollo de una antítesis. Estas novelas cortas fueron al mismo tiempo bosquejos y epígonos de novelas anteriores que el propio mercado demandaba y que dio lugar a recopilaciones o refundiciones de otras obras. Más allá de recorrer diligentemente las tramas redundantes que formulan una y otra vez las obras del colombiano, me interesa poner de manifiesto en este análisis los discursos antitéticos que afloran de manera sintomática en los trasuntos familiares que recopila y a los que subyacen tres claves historicistas que por extensión definen su obra durante el periodo pergeñado: a. La entelequia geopolítica del Norte versus Sur, b. Las relaciones entre el Estado y la Iglesia, Pascendi Dominici Gregis, y c. La disparidad del código de honor masculino y femenino. Considero que esos índices historicistas y sociológicos pululan en la obra del colombiano como hitos claves para su comprensión y contextualización, los cuales convergen en los postulados y valoraciones de un nuevo público formado por lectoras.

\section{La entelequia geopolítica: Norte versus Sur}

Carlos Jáuregui señala respecto al popular ensayo que Vargas Vila publicara a principios de siglo, Ante los bárbaros (1902), el giro insospechado que el autor hace para mostrar de forma apologética la barbarie latinoamericana, donde Latinoamérica representaría una mezcla de todas las barbaries y de todas las civilizaciones (353). La obra aquí analizada, El alma de la raza (1916), ya distante en el tiempo del ensayo que escribiera a comienzos del siglo, se concibe en una dimensión muy diferente pues el contexto en Europa es el de la Primera Guerra Mundial (1914-1918). El recurso caricaturesco, lejos de la estructura rígida ensayística y del tono sublime del mismo, hace que el discurso vargasvilesco adquiera otra significación rayana en la transgresión misma de la propia novela y del ensayo como tal. En el marco de la novela corta, el pensamiento ensayístico aflora de manera ridiculizada auspiciado por las figuras y la acción. El planteamiento es tan heterodoxo que llega al punto de plantear una revalorización misma de los proyectos que definieron el ensayo modernista finisecular, epitomizados por obras como el Ariel de Rodó.

La dicotomía entre latinos y anglosajones surgió a finales del siglo XIX, como resultado de la percepción "decadente" y "degenerada" imperante en Europa, fruto de una visión autorreflexiva que las clases intelectuales tenían respecto al mundo industrializado. La fuerza política y económica dominante engendrada por los países sajones -inicialmente representada por Alemania, a raíz de la derrota sufrida por Francia en 1870, o de la española frente a EEUU en 1898-, hizo que una conciencia latinista

Revista Iberoamericana, Vol. LXXXI, Núm. 252, Julio-Septiembre 2015, 767-785 ISSN 0034-9631 (Impreso) 
se expandiera en diferentes frentes contra el sajonismo o, en términos geopolíticos, frente al nordicismo. En reciprocidad a esa visión extrapolada, una posible alianza latina serviría para realzar y devolver la añorada grandeza frente al poder de los países anglosajones entonces en alza. La difusión de esta polémica transcendió a América Latina encarnada en el naciente nacionalismo, los movimientos migratorios y la búsqueda de una identidad panamericana. Varias fueron las publicaciones que ayudaron a difundir esa latinidad en Hispanoamérica: Renacimiento Latino en Santiago de Chile, La España Moderna y La Revista Latina de Buenos Aires (Litvak, España 161). Esa dicotomía de la "raza latina" frente a la bárbara se difuminó a medida que el siglo XX generó una nueva conciencia social. En ese momento las divisiones no fueron tan palpables debido a la imposibilidad de importar una visión eurocéntrica y adaptarla a la complejidad y amalgama intrínseca al mundo americano, que en aquellos momentos se hacía más incoherente por los movimientos migratorios vigentes. Pronto se pasó del sentimiento de euforia al de escepticismo.

La división entre aliadófilos y germanófilos, ya comenzada la Primera Guerra Mundial, no fue igualmente reveladora en Europa. Aunque la mayoría de intelectuales apoyaron la causa aliadófila, otros sectores vinculados a la medicina, al derecho o a la instrucción militar, se sumaron a la causa germanófila. A pesar de la neutralidad que mantuvieron todos los países hispanoamericanos, las declaraciones intencionales o intencionadas de los intelectuales afines a cualquiera de los bandos se distorsionaron a medida que la Primera Guerra Mundial hizo estragos en los diferentes estratos sociales. Por un lado, forzó al exilio a muchas personas y, por el otro, contradictoriamente, favoreció económicamente a los países neutrales, los cuales funcionaron como proveedores de aquellos otros países en lid o acogieron a los inmigrantes procedentes de esos mismos países.

En su novela Vargas Vila afronta estas fluctuaciones sociales desde la hipérbole y la deformación, convirtiendo el discurso ideológico latinista y germanista en una pantomima que se recrea en la infamia de los postulados vigentes. El alma de la raza muestra una de las tramas más reiteradas en la obra de Vargas Vila, tratada ya con éxito en su reconocida novela Ibis, que también se fundamentaba en una crítica alegórica a la institución familiar burguesa (García Sánchez, "Nacionalismo"). Además de estar envuelta en un halo de recreación decadente, se plasma la naciente dialéctica finisecular de la identidad Latinoamericana que converge en la dicotomía entre el norte y el sur, entre aliadófilos, sinónimos de francófilos, y germanófilos o defensores del Imperio alemán. Entre ambos sectores subyacen aquellos que vislumbraban en la nación francesa el modelo progresista y liberal frente a la férrea disciplina alemana, eje del conservadurismo y la maquinaria burocrática.

Mediante la hipérbole, El alma de la raza rebate esa visión antitética. El narrador, Flavio, consignado en primera persona, nombre de origen latino, perteneciente a la familia Flavia, de los rubios, narra los incidentes que lo han llevado a escribir con

Revista Iberoamericana, Vol. LXXXI, Núm. 252, Julio-Septiembre 2015, 767-785 ISSN 0034-9631 (Impreso)

ISSN 2154-4794 (Electrónico) 
sus muñones sobre el "Type writer" (3) en la ciudad de New York. ${ }^{4}$ La obra comienza con un breve recorrido narrativo autográfico sembrado de un tono trágico: su "padre despedazado por la carrera de un potro indómito" (4) al que le sigue la madre que muere por su "tristeza inconsolable" (4).

La relación paterno-filial (Flavio/Manlio) constituye el más descriptivo ejemplo de la escabrosa humanidad ante un ataque de Manlio por intoxicación etílica. Sumidos en la desidia del alcohol y las drogas, el suicidio familiar se nutre adjetivalmente del vacío nihilista. La visita de Aureliana (prima del narrador) y de Germania, su hija, conduce la narración hacia nuevos derroteros que delimitan la acción de los personajes. El espíritu artístico y aristocrático de Germania, la hija (las dotes pictóricas y musicales, el conocimiento de la lengua francesa, son atributos que la definen), contrasta con la ignorancia y el "mal gusto" de su madre, Aureliana.

Germania se acercó a leer, y con voz baja y pausada, leyó:

Luxure, fruit de norte à l'arbre de la vie!...

Luxure, idole noir et terrible.../je te salue...

en el momento en que la salutación terrible de esos versos despertaba y, gritaba grandes cosas, negras y, rojas en el fondo de sus entrañas de virgen, yo, vi lucir en sus ojos, como en los de su madre, el mismo resplandor orgiástico, la misma pasión ninfómana, que dormitaba tras de los párpados semicerrados de la monja lésbica, el morbo impuro, el terrible morbo ancestral, circulaba por su sangre y, agitaba su psiquis, con el ardor del germen hereditario; (25)

El amor de Flavio por Germania da inicio al resentimiento y venganza respecto a las relaciones paterno-filiales entre Flavio y Manlio, pues ambos tienen el mismo objeto de deseo, Germania. La fatalidad de los personajes se refuerza en el recorrido narrativo con todas las dosis dramáticas románticas; mientras que Manlio, sumido en la desesperación de las crisis epilépticas se dedica a la consumición de éter, Aureliana, "presa de delirios eróticos, se entregaba a excesos de histeria, que eran el escándalo de la servidumbre, y, de los escasos campesinos, que había en los alrededores" (54). Como desenlace final, el padre, Flavio, hiere mortalmente con un sable a su hijo. Amén del horror descriptivo y sanguinario con el que se dramatiza la acción final, el subtexto que sostiene el movimiento figurativo está basado en la acción filicida por el amor/ celos que ambos comparten hacia la joven Germania. La novela corta El alma de la raza, mediante el uso de figuras simbólicas parodia la disputa finisecular y ridiculiza

4 Vargas Vila agrega el texto de El alma de la raza al inicio de su novela posterior Lirio negro-Germania (1920?). Esta novela es a su vez el resultado del desglosamiento de El alma de los lirios (1904) en la trilogía Lirio blanco-Delia (1920?) -primero publicada como El cisne blanco (1917)-, Lirio rojoEleonora (1920?) y Lirio negro. Nota de los editores.

Revista Iberoamericana, Vol. LXXXI, Núm. 252, Julio-Septiembre 2015, 767-785 ISSN 0034-9631 (Impreso) ISSN 2154-4794 (Electrónico) 
la constricción dialéctica entre el norte y el sur, entre aliadófilos y germanófilos que obcecó la búsqueda de la identidad latinoamericana. El texto proyecta ese poder autodestructivo que amenaza los ideales de la familia sajona y latina y es publicado cuando el contencioso de la Primera Guerra Mundial en pleno proceso ha desfigurado cualquier polémica que le precediera.

Ni el indigenismo, ni el negrismo, ni aún el orientalismo fueron salvaguardias de la obra del colombiano, y no llegaron a intuirse como divisa identificadora en el resto de su obra. Por otro lado, el exceso decadente campea a sus anchas y se embelesa en las referencias de adicción y morbidez de los personajes con respecto a la morfina, al éter y al alcohol, en el lujo desmedido de mármoles, pieles, cristales y maderas exóticas con que describe la decoración del palacete y por extensión el resto de la obra. Ese lujo desenfrenado atrajo a un número de lectores que más allá de una polémica ideológica de la que eran referente inmediato, se sentían fascinados por ese lenguaje artificioso y fatuo en el que veían culminadas las fantasías más sublimes a las que jamás pudieran acceder. Es posible contender que el fin catártico pretendido justificó el género trágico elegido por el autor. Por otra parte, esa exuberancia léxica y descriptiva contrasta con el beneficio mórbido de aquellos lectores que encontraron cierto resarcimiento social contra los ideales de la clase aristocrática, anquilosada y en proceso de extinción.

\section{PASCENDI DOMINICI GREGIS}

Entre los múltiples condicionamientos que llevaron a la inmigración europea hacia Latinoamérica, además de los aspectos económicos que originan tales movimientos, el anticlericalismo se mostró como un factor añadido. Éste fue el cuño de muchos de aquellos inmigrantes, en muchos casos encubierto en otras ideologías de tinte liberal: anarquistas, socialistas e incluso masónicas. El tornaviaje vargasvilesco ofrece una dimensión más del anticlericalismo y del transvase ideológico que opera entre ambos continentes.

A pesar de la situación privilegiada que mantuvo la Iglesia respecto a los gobiernos conservadores, de sobra se ha atestiguado la relación no fluida-forjada en una dinámica antagonista- entre la Iglesia y el modernismo. Los preámbulos del Primer Concilio Vaticano (1870) ya fueron premonitorios, pasando por las manifestaciones expresas contra el modernismo cuando León XIII publicara su "Rerum Novarum", hasta que el Papa Pío X lanzara en 1907 su encíclica "Pascendi Dominici Gregis" en que exponía los "errores" del modernismo. Como colofón, la promulgación por parte del propio Pío X del "Motu Proprio: Sacrorum Antistitum”, también conocido como «Juramento antimodernista», el cual debía ser pronunciado por cualquiera que quisiera conservar o acceder a un oficio eclesiástico. El clima inquisitorial vivido da fe de la paranoia existente, exacerbada por el requerimiento, en muchos casos, de la investigación por parte de la Iglesia. En ese

Revista Iberoamericana, Vol. LXXXI, Núm. 252, Julio-Septiembre 2015, 767-785 ISSN 0034-9631 (Impreso)

ISSN 2154-4794 (Electrónico) 
sentido, a pesar de que las obras de Vargas Vila no fueran expresamente prohibidas, la Iglesia reaccionó declarándolo amoral, demonizando su obra y, a contracorriente de lo creído popularmente, no fue excomulgado. ${ }^{5}$ La reacción contra las nuevas maneras de narrar el mundo debe entenderse desde el repliegue que la Iglesia adopta tras la pérdida de poder frente a las políticas liberalistas finiseculares y los dogmas que el positivismo divulgaba, causa y efecto del proceso de secularización creciente:

Andan clamando que el régimen de la Iglesia se ha de reformar en todos sus aspectos, pero principalmente en el disciplinar y dogmático, y, por lo tanto, que se ha de armonizar interior y exteriormente con lo que llaman conciencia moderna, que íntegramente tiende a la democracia; por lo cual, se debe conceder al clero inferior y a los mismos laicos cierta intervención en el gobierno y se ha de repartir la autoridad, demasiado concentrada y centralizada.

Las Congregaciones romanas deben asimismo reformarse, y principalmente las llamadas del Santo Oficio y del Índice.

Pretenden asimismo que se debe variar la influencia del gobierno eclesiástico en los negocios políticos y sociales, de suerte que, al separarse de los ordenamientos civiles, sin embargo, se adapte a ellos para imbuirlos con su espíritu.

En la parte moral hacen suya aquella sentencia de los americanistas: que las virtudes activas han de ser antepuestas a las pasivas, y que deben practicarse aquéllas con preferencia a éstas. Piden que el clero se forme de suerte que presente su antigua humildad y pobreza, pero que en sus ideas y actuación se adapte a los postulados del modernismo. Hay, por fin, algunos que, ateniéndose de buen grado a sus maestros protestantes, desean que se suprima en el sacerdocio el celibato sagrado.

¿Qué queda, pues, intacto en la Iglesia que no deba ser reformado por ellos y conforme a sus opiniones? (Pío X)

El Modernismo de Vargas Vila encarna lo que alude indirectamente la encíclica de Pío X y se hace patente en la práctica totalidad de las obras de "El Divino" (Flor del fango, María Magdalena, Las rosas de la tarde) y con todos los diferentes dogmas y asuntos eclesiásticos que suscita y debate: la relación de la Iglesia Católica con otras religiones, por ejemplo, los judíos; la situación de las diferentes jerarquías eclesiales; la imaginería religiosa; la interpretación bíblica; la humanización de Jesucristo; la situación de la mujer en la institución eclesiástica, el divorcio, entre otras. Muchas de las novelas cortas son una extensión más de esos temas, otras se constituyen en el objeto codiciado por el autor ante los mismos (El medallón, Desiderio). Hemos elegido la novela corta $E l$ milagro por vincularse expresamente, desde el título, a los motivos bíblicos incrustados en la trama, ya sea mediante la interpolación de figuras, o bien mediante una simbología codificada en torno a esa temática religiosa que el propio argumento revela.

5 Ver Gilberto Gómez Ocampo.

Revista Iberoamericana, Vol. LXXXI, Núm. 252, Julio-Septiembre 2015, 767-785 ISSN 0034-9631 (Impreso) ISSN 2154-4794 (Electrónico) 
El motivo bíblico de El milagro, en alusión preferente a la figura bíblica de la Magdalena, logra la denuncia de las costumbres populares que seguían inmersas en las creencias populares fundamentadas en el fraude, y tan peculiares desde la Baja Edad Media, al mismo tiempo que codifica otra polémica que llega incólume hasta nuestros días con respecto a los impedimentos surgidos entre el deseo sexual y el celibato. Ambas oposiciones, la fe y el fraude público, el deseo y la castidad, son los catalizadores de réplica que Vargas Vila emplaza contra la Iglesia.

Un joven sacerdote, Patricio, figura simbólica de Jesús, egresado del seminario es destinado a un pequeño pueblo. El conflicto generacional entre el joven sacerdote y el viejo cura inicia el motivo de desarrollo de la trama, sumando a la condena explícita y expulsión del pueblo de una prostituta, Minerva, quien por su nombre refleja la figura mitológica homóloga a Atenea en la tradición griega, diosa de la sabiduría:

-Y, ¿por qué no la expulsan?- dijo con una voz autoritaria.

-Expulsarla... y ¿quién?; el Alcalde que podía hacerlo es su amante, y, su hijo un niño que hasta ayer no más jugaba en las calles, también es su querido...(5)

La conversión de Minerva, joven meretriz, a la vida recatada corresponde a la atracción sexual que la misma mantiene hacia el joven sacerdote. El tormento interior del sacerdote se suma a los intentos de Minerva por seducirlo:

[...] de súbito la Minerva abrió los ojos hechos desmesurados, los fijó tenaces y fascinadores en el joven, y abrazándose locamente a él, le gritaba:

-Sálveme, Padre, sálveme;

y lo trajo contra su seno;

y lo beso en sus ojos, en los labios, en todas partes de su cuerpo...

por largo tiempo no se oyó en la estancia sinó un rumor de besos, que al fin se oyeron lentos y fatigados, como una lluvia de nardos, cayendo deshojados en el corazón silencioso de la Noche que nacía. (15)

El enclaustramiento de Minerva debido a la "enfermedad", su embarazo, configura el fraude y el montaje "milagroso" de su santificación. De este modo, su casa se convierte en templo de peregrinación, como antes lo había sido el prostíbulo, con las consabidas y sustanciosas ganancias. La reaparición del hijo de Minerva en última instancia, quien la mata con un estilete en el costado, da el referido fin trágico a la obra.

Por supuesto, la Iglesia fue un agente económico aliado en su mayor parte a las clases pudientes. La dinámica eclesial supuso una doble dirección en la adopción de políticas. Por un lado, el apoyo económico a las políticas liberales de las diferentes naciones de América Latina contrasta con el modelo conservador que se proclama en las encíclicas y pastorales finiseculares. Por el otro, la sumisión de las clases menos

Revista Iberoamericana, Vol. LXXXI, Núm. 252, Julio-Septiembre 2015, 767-785 ISSN 0034-9631 (Impreso)

ISSN 2154-4794 (Electrónico) 
beneficiadas disiente del reaccionismo que inspira a las clases medias, favorecidas por esas políticas económicas liberales. Sin embargo el modelo vargasvilesco anticlerical es válido internacionalmente y se configura en ese proceso de secularización internacional que encuentra respuesta en un público ávido de argumentos frente a las contradicciones sociales y religiosas que afloran en su entorno más inmediato: el párroco del barrio, el cura del pueblo, el sacristán o las monjas del convento. Los movimientos anarcosindicalistas urbanos en pleno apogeo en España a principios de siglo, especialmente en Barcelona, encontraron en este tipo de obras un estímulo ideológico.

La reapropiación de la simbología bíblica, su parodización, el tono sardónico y mordaz, la provocación satírica e incluso pornográfica -los parámetros sociológicos hoy nos hacen sonreír-fueron en toda la obra del colombiano el germen de sus mayores éxitos públicos, que supusieron el mayor reclamo y el éxito recaudado.

\section{LOS CÓDIGOS DEL HONOR MASCULINO Y FEMENINO}

Además de otras ramas afines, la sociología se convirtió en la ciencia que encauzó los estudios sobre la institución familiar en todas sus dimensiones (Henri de Saint Simon, Auguste Comte, Alexis de Tocqueville, Émile Durkheim, Max Weber, Karl Marx, Georg Simmel). Al hablar del núcleo familiar de clase media de finales del siglo XIX y comienzo del siglo XX en Hispanoamérica, se sobreentiende que la mujer, eje de la institución familiar, se formula como el instrumento básico de reproducción y mantenimiento del orden social frente al hombre que adquiere el rol protector. El pater familiae, en su labor protectora, relega a la mujer y a los hijos a un segundo plano. Para tal labor protectora se inviste de todas las herramientas útiles que le provee el orden social, ya sean de cariz social y religioso (honor), económico (puesto de trabajo) o legal (privilegios). A pesar de la ruptura colonial que se produce a principios del siglo XIX, la estructura social vigente no cambió. La unidad familiar conllevó por parte de la mujer su sumisión absoluta, su predestinación hacia el matrimonio o como opción secundaria hacia la iglesia, las labores relacionadas con la manutención del hogar y con el cuidado de los hijos, y por supuesto, la preservación del recato y la virginidad que aglutinaban el concepto del honor.

El desfase producido por la industrialización entre los núcleos urbanos y los rurales, las divergencias que operaron entre las clases medias emergentes y el proletariado, así como el desajuste entre el bienestar económico y el progreso social provocó una situación de constante confrontación entre el Estado y la sociedad. El nacionalismo en ciernes a finales del siglo XIX supo utilizar la familia como ente de control frente a la incertidumbre generada por los grandes cambios confluyentes en el periodo finisecular y que se postergan hasta bien entrado el siglo XX. Las discrepancias legales que alcanza el concepto de honor en las legislaciones hispanoamericanas frente a las de tradición

Revista Iberoamericana, Vol. LXXXI, Núm. 252, Julio-Septiembre 2015, 767-785 ISSN 0034-9631 (Impreso)

ISSN 2154-4794 (Electrónico) 
sajona, puestas de manifiesto en los códigos civiles de los diferentes países o en los discursos eclesiales del siglo XIX, está en relación directa con los cambios sociales que se produjeron en toda Europa e Hispanoamérica, y cuya máxima expresión irrumpe ante la incorporación de la mujer al mercado de trabajo, las primeras causas feministas en los centros urbanos y la relajación de las normas morales. A pesar de estas lentas transformaciones, la mujer estuvo relegada en su mayor parte al núcleo familiar.

Es notoria en la obra de Vargas Vila la misoginia que impregna toda su obra y que desvela las contradicciones que marcaron su narrativa. El marco simétrico que opera en las relaciones familiares viene concebido desde los modelos de comportamiento sometidos a la disposición "natural" frente a la "cultural" en los cuales aparece la división genérica. Este modelo aparece racionalizado sin llegar a deconstruirse, hasta tal punto que si la mujer diligente y obediente no comulga con esos patrones, rompe con el honor familiar. Las grandes reformas liberales constitucionales chocaban con las medidas de intervención en la esfera privada, cuyos principales objetivos eran la organización familiar, la defensa a ultranza del honor masculino y femenino, el mantenimiento del pudor y las buenas costumbres, construyendo así una forma de representación individual en contraste con las medidas políticas progresistas.

En periodos de inseguridad cultural, cuando surgen los miedos de regresión y degeneración, la necesidad de estrictos controles de seguridad respecto a las definiciones de género, así como de raza, clase y nacionalidad se hacen especialmente intensas. (Showalter 4, traducción mía)

El honor, marchamo masculino de identidad y tabla rasa del control de clase, raza, género y nacionalidad, se encubrió en la familia tradicional de un doble filo, tal como se esboza en la novela El Maestro de Vargas Vila. En el sello anticlerical vargasvilesco se filtra la defensa humana del maestro rural, prototipo filantrópico, que debido a las vicisitudes de la vida se tiene que confrontar a una sociedad anclada en una moral estoica, provinciana, y por otro lado, en la férrea defensa del "honor", codificada por la ley del divorcio que la Iglesia rebate. Un joven ingeniero, Don Fausto, desencantado de su vida matrimonial pues su mujer lo traiciona, huye a un pueblo de la meseta andina en dónde se dedica a la vida del magisterio:

viviendo en una sociedad, corrompida por todos los virus religiosos, y, en la cual por ende, no existía esa ley, reparadora del honor, que es, la ley del divorcio, y tuvo que dejar su honra, como una joya más en el pecho de la adúltera, que la llevó por todos los mercados, y, la ultrajó con el abrazo de todos los hombres... (14)

Enamorado de una joven del pueblo donde reside y de la que espera un hijo, y ante la imposibilidad de casarse con la misma - pues hubiera provocado una situación

Revista Iberoamericana, Vol. LXXXI, Núm. 252, Julio-Septiembre 2015, 767-785 ISSN 0034-9631 (Impreso)

ISSN 2154-4794 (Electrónico) 
de bigamia debido a la imposibilidad de anular su anterior matrimonio-, huye una vez más. Muchos años después, Don Fausto es nombrado maestro en un nuevo pueblo. Allí, su relación de amistad con uno de sus pupilos más avanzados le lleva a descubrir que se trata de su nieto, el hijo de su hija que había sido fruto de la aventura amorosa. El hecho de que el protagonista no pueda revelar a su propia hija que él es su padre o a su nieto que él es su abuelo, acarrea trágicamente todos los problemas conectados con las convenciones sociales:

Se hizo asiduo de la casa y, todas las tardes, después que cerraba la escuela, podía vérsele llegar llevando el niño de la mano, $\mathrm{y}$, sentarse al lado de la madre en el corredor, hablándole mientras ella bordaba, esperando el regreso del marido, y, el niño jugaba en el jardín cercano, bajo la mirada vigilante de los dos, y el crepúsculo caía sobre ellos lentamente, envolviéndolos en sus reflejos, como en una misma bendición;

y, el viejo sonreía a la vida, feliz con ese girón de ventura, que caía sobre su ancianidad, como el último harapo que cubre el cuerpo de un mendigo, moribundo en la noche; lentamente, confusamente, como un silbido de víperas bajo el matorral, un rumor se alzó del corazón del pueblo y fue, circulando de boca en boca, como una avispa envenenada; -El Maestro está enamorado de Paula... (28)

Condenado al silencio, la relación afectuosa entre el maestro y su hija entró en los preámbulos de las murmuraciones y el odio, primero de la familia y después de todo el pueblo contra el maestro, quien termina siendo lapidado y apaleado hasta la muerte, sin haber revelado su identidad a sus seres amados.

Vargas Vila se aprovisiona de múltiples mecanismos retóricos para apuntalar su narración y su intención ideológica: en un primer momento utiliza un desplazamiento del concepto de honor, noción anclada en la tradicionalidad, arma popular de la que se apropia el colombiano para hacer frente al conservadurismo religioso que se opone al divorcio. La justificación de la idea del honor surge sólo como defensa del divorcio. La honra queda restituida de este modo en manos masculinas, en menoscabo de la dignidad femenina. Por otro lado, utiliza de nuevo el final trágico basado en la tradición bíblica del lapidamiento de María Magdalena para denunciar las infamias cometidas por la Iglesia contra el maestro, quien se convierte en una reformulación masculina de la mujer defendida por Jesús. Para esos primeros lectores mediados por una educación religiosa tradicional, correligionarios mayores de los valores tradicionales que la familia aunaba, el uso de asociaciones simbólicas y elementos religiosos supuso una forma de acercamiento y reflexión a los postulados revulsivos contra los que las instituciones conminaban a la población, ya fuera desde el púlpito eclesial, la tribuna del congreso, o desde la tarima magisterial. 


\section{Conclusiones}

El uso populista de la filosofía existencialista de Schopenhauer y Nietzsche, así como de las nociones psicoanalíticas freudianas, converge en la obra de Vargas Vila como caldo de cultivo del ocaso modernista y naturalista en el que se sitúa su obra. El hibridismo experimental novelesco que ensayara Vargas Vila al mezclar los elementos hiperbólicos que caracterizan sus obras, ya fuera por las acciones de sus personajes, los temas revulsivos, la sintaxis pomposa o el léxico exultante, o por los elementos recurrentes de la tragedia clásica, fueron confidentes de un contexto histórico inmediato que demandaba nuevos contenidos.

Por otro lado, a medida que el peso de la representación femenina cuaja social y representativamente en toda Hispanoamérica, la lectora femenina surge como emblema individual de una compleja red de relaciones sociales cambiantes, como agente primario de esa propia transición: trabajadora, madre, alcohólica, viuda, divorciada, prostituta, lectora, hijastra, adúltera, soltera, escritora. Se trata de un proceso que anula la privación y encumbra lo privado como espacio de descubrimiento de referencia y de acción social. Las publicaciones de "La Novela corta" suponen un referente del imaginario comunitario de ciertos sectores que privatizan la literatura como herramienta social. Las tensiones que impregnaron la sociedad española, y por extensión toda Latinoamérica, de comienzo de siglo aúnan los pormenores emocionales y sentimentales de un sinnúmero de lectoras que identificaban su batalla diaria -ajena a las trincheras de la Primera Guerra Mundial- con los asuntos inmediatos que les incumbían, o aquellos que satisfacían el morbo social, ora fuera un caso de incesto, de prostitución, de separación, de violación, de aborto, ora de drogadicción o alcoholismo.

Cabe inquirir entonces en una valoración de la obra de Vargas Vila, no por el gesto demodé de su autor o de su crítica, anclada en muchos casos en valoraciones morales o canónicas, sino por los espacios, tanto públicos como privados, que sus lectoras ocuparían socialmente. La familia que Vargas Vila analiza en sus obras, atendiendo a las consideraciones antes descritas, se identificó por exceso o por defecto con ciertos sectores del tejido social hispanoamericano de principios de siglo. El usufructo estético de la alegoría familiar permitió en general a todos los novelistas modernistas una abstracción universalista de un espacio transnacional que les confería su estatus de viajero, diplomático o exiliado. No obstante, la obra de "El Divino Vargas Vila" atisbó con sus parábolas (des)familiares modernistas un espacio insurgente.

Revista Iberoamericana, Vol. LXXXI, Núm. 252, Julio-Septiembre 2015, 767-785 ISSN 0034-9631 (Impreso)

ISSN 2154-4794 (Electrónico) 


\section{OBRAS CITADAS}

Acosta, Julia. “Contestando un saludo”. La Revista Blanca 56 (1925): 37.

Carrillo, Victor. L'Infra-littérature en Espagne au XIXe et XXe siècles: du roman feuilleton au romancero de la guerre d'Espagne. Grenoble: Presses Universitaires, 1977.

Catelli, Nora: "Buenos libros, malas lectoras: la enfermedad moral de las mujeres en las novelas del siglo XIX”. Lectora: Revista de Dones i Textualista 1 (1995): 121-133.

Cornejo, Ignacio. "Sobre Vargas Vila y sus obras". La Revista Blanca 43 (1925): 37-38.

Deleuze, Gilles y Félix Guattari. El antiedipo. Barcelona: Paidós, 1985.

Foucault, Michel. Las palabras y las cosas. Una arqueología de las ciencias humanas. Buenos Aires: Siglo Veintiuno, 1968.

García Sánchez, José M. “El nacionalismo de José María Vargas Vila en Ibis”. Revista de Estudios Colombianos 16 (1996): 6-11.

La novela corta de José María Vargas Vila. New Orleans: UP of the South, 2000.

Gómez Ocampo, Gilberto. "Secularización, liturgia y oralidad en la obra de Vargas Vila". Juan Villegas Morales, ed. Actas Irvine-92. Irvine: U of California P, 1994. 259-267.

Jáuregui, Carlos. Canibalia: canibalismo, calibanismo, antropofagia cultural y consumo en América Latina. La Habana: Casa de las Américas, 2005.

Litvak, Lily. España 1900: modernismo, anarquismo y fin de siglo. Barcelona: Anthropos, 1990.

"La idea de la decadencia en la crítica antimodernista en España (1888-1910)". Hispanic Review 45/4 (1977): 397-412.

Montseny, Federica. "La obra de los mediocres". La Revista Blanca 30 (1924): 16-19.

“Más sobre Vargas Vila”. La Revista Blanca 42 (15 feb. 1925): 1-2.

"Las mujeres y Vargas Vila". La Revista Blanca 57 (1925): 1-3.

Mota, Matilde. "Otra opinión sobre Vargas Vila y su obra". La Revista Blanca 56 (1925): 37-38.

Pío X. "Pascendi Dominici Gregis". Vaticano. 25 sept. 2013. <http://www.vatican. va/holy_father/pius_x/encyclicals/documents/hf_p- x_enc_19070908_pascendidominici-gregis_sp.html>. 1 nov. 2009.

Serrano, Carlos y Serge Salaün. Los felices años 20. España crisis y modernidad. Madrid: Marcial Pons, 2006.

Serret, Juan. “Un poco más sobre Vargas Vila”. La Revista Blanca 52 (1925): 38-39. "Un poco más sobre Vargas Vila" (cont). La Revista Blanca 53 (1925): 38. "Vargas Vila". La Revista Blanca 40 (1 oct. 1924): 39.

Showalter, Elaine. Sexual Anarchy: Gender and Culture at the Fin de Siècle. New York: Penguin Books, 1991.

Torres Rioseco, Arturo. "Francisco Contreras y Vargas Vila". Hispania 16/4 (1933): 399-400.

Revista Iberoamericana, Vol. LXXXI, Núm. 252, Julio-Septiembre 2015, 767-785 ISSN 0034-9631 (Impreso)

ISSN 2154-4794 (Electrónico) 
Vargas Vila, José María. El alma de la raza. Madrid: Novela corta, 1916. El maestro. Madrid: Novela corta, 1921. El milagro. Madrid: Novela corta, 1919. 
